This item was submitted to Loughborough's Research Repository by the author.

Items in Figshare are protected by copyright, with all rights reserved, unless otherwise indicated.

\title{
Repeat receipts: a device for generating visible data in market research
} focus groups

PLEASE CITE THE PUBLISHED VERSION

http://dx.doi.org/10.1177/1468794104047231

PUBLISHER

(c) Sage

VERSION

AM (Accepted Manuscript)

LICENCE

CC BY-NC-ND 4.0

\section{REPOSITORY RECORD}

Puchta, Claudia, Jonathan Potter, and Stephan Wolff. 2019. "Repeat Receipts: A Device for Generating Visible Data in Market Research Focus Groups". figshare. https://hdl.handle.net/2134/15077. 
This item was submitted to Loughborough's Institutional Repository (https://dspace.lboro.ac.uk/) by the author and is made available under the following Creative Commons Licence conditions.

\section{creative
commons}

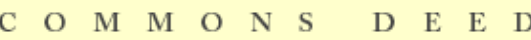

Attribution-NonCommercial-NoDerivs 2.5

You are free:

- to copy, distribute, display, and perform the work

Under the following conditions:

Attribution. You must attribute the work in the manner specified b the author or licensor.

Noncommercial. You may not use this work for commercial purposes.

No Derivative Works. You may not alter, transform, or build upon this work.

- For any reuse or distribution, you must make clear to others the license terms of this work.

- Any of these conditions can be waived if you get permission from the copyright holder.

Your fair use and other rights are in no way affected by the above.

This is a human-readable summary of the Leqal Code (the full license).

\section{Disclaimer 만}

For the full text of this licence, please go to: http://creativecommons.org/licenses/by-nc-nd/2.5/ 


\section{Repeat receipts: a device for generating visible data in market research focus groups}

CLAUDIA PUCHTA

University of Applied Sciences, Lueneburg, Germany

JONATHAN POTTER

Loughborough University, UK

STEPHAN WOLFF

University of Hildesheim, Germany

ABSTRACT Market research focus groups generate three types of data: first, representatives of commissioning companies or organizations watch the group from behind a one-way mirror; second, they receive a video of the group discussion; third, they are given a report of the focus group. This article analyses how the required data are interactionally produced to be visible for the people behind the one-way screen, for the video and for the report. It describes the phenomenon of repeat receipts as a central device for producing visible data. Repeat receipts are sequences where the moderator repeats participants' contributions, typically with intonational cues that mark completion. Repeat receipts have several functions. They can (a) highlight central market-research relevant terms from participants' responses; (b) strip off rhetorical relations by repeating utterances in a decontextualized manner; (c) summarize contributions in repeating contributions of different authors as if of one voice; (d) cover conflict in repeating potentially contradictory contributions as discrete statements; (e) socialize responding by providing templates for the required contributions. Repeat receipts help shape the focus group interaction to generate visible data for the overhearing audience, the video and the report. The article ends with a comparison of repeats in market research focus groups, standardized surveys and news interviews.

KE Y WOR DS : conversation analysis, data visibility, discursive psychology, focus groups, moderation, repeat receipts

Published as:

Puchta, C., Potter, J. \& Wolff, F. (2004). Repeat receipts: A device for generating visible data in market research focus groups, Qualitative Research, 4, 285-309. 


\section{Introduction: producing visible data}

\begin{tabular}{|c|c|}
\hline M: Rick & $\begin{array}{l}\text { And the characteristics of this } \uparrow \text { pe:rson } \\
\text { (. .) if you can imagine them, }\end{array}$ \\
\hline Mary & $\frac{\text { Powerful, }}{(.)}$ \\
\hline M: Rick & ${ }^{\circ}$ Powerful, ${ }^{\circ}$ \\
\hline Hannah & $\begin{array}{l}\overline{\mathrm{DOMIN}} \downarrow \mathrm{ANT} \\
(\text {. ) }\end{array}$ \\
\hline M: Rick & Dominant, \\
\hline
\end{tabular}

This sequence is taken from a market research focus group. Rick is the moderator, and Mary and Hannah are the participants. In this article we will analyse such talk in market research focus groups.

The relation between interaction and the results of market research focus groups is quite complex. The companies or organizations who commission the group pay for three kinds of output. First, they may have a representative who watches the interaction from behind a one-way mirror. Second, they will be given a video of the interaction. Third, they will be given a report of the interaction written by the moderator (which typically summarizes themes and gives sample quotes of people's views).

Typically, none of these forms of output takes priority over the others. This means that the moderator is the central part of the data production. He or she can, for example, display the importance of something by drawing attention to it (for example, by repeating it) or display its irrelevance to the business of the group by ignoring it. This will be apparent to the client whether through the one-way mirror or on the video, or in what is quoted in the report. The visibility of the data in market research groups is a much more direct issue than in a social science focus group where considerable sifting and coding may go into the production of a data set for analysis. There would be no expectation that a research article, say, would include the raw interaction as its data and finding. Something more is going on in market research groups than the general orientation to producing visible, rational and accountable interaction as has been documented in ethnomethodological research (Garfinkel, 1967). There is a special sense of visibility at work where the unedited record of the focus group is itself the result of the research. This article focuses on one procedure by which such visibility is achieved.

This article deals with a basic practice in market research focus groups, which is to repeat parts of group members' contributions. We will suggest that this is an important device for achieving a number of market research relevant tasks. In the course of the article, we will first make a series of descriptive observations that identify features about the moderators' receipts in the form of repetitions and, second, we will offer explanations as to what this basic practice is doing and why it should be here. We will show how the interaction in market research focus groups, in an important sense, is the findings. This means that 
a moderator technique such as eliciting and repeating short descriptions is not just there to make the job of report writing simpler; it guides the interaction in a way that makes the opinions, beliefs and attitudes clearly visible. Before going on to describe the market research focus group as a visible data production machinery, however, we will describe our analytic approach.

\section{Studies of the work of social research}

In the last decade a new strand of research has developed which comprises qualitative studies of qualitative and quantitative social research itself. These studies investigate interviews and focus groups as forms of talk in their own right and apply conversation analysis (CA) and, more recently, discursive psychology (DP) to methodological practices in specific research situations. In one of the first studies of this kind Suchman and Jordan (1990) considered the working of face-to-face survey interviews. They identified a number of departures of actual survey practices from the idealizations and claimed that however much effort is put into improving question wording, interviewers and respondents will always need to negotiate the meaning of both questions and answers. Developing this tradition of work, Schaeffer and Maynard (1996) noted a preponderance of deviant cases, emphasizing the need for interviewers to continually manage the sense of the question for the respondent. Work in this tradition has developed in recent years, with further work on standardized surveys, open-ended interviews and other psychological tests (Antaki, 1999; Antaki et al., 2000; Antaki and Rapley, 1996; HoutkoopSteenstra, 1995, 1996, 1997, 2000; Maynard et al., 2002; Maynard and Schaeffer, 1997, 2000; Rapley, 2001; Rapley and Antaki, 1996).

Recently researchers have started to study interaction in focus groups and how that interaction is organized (Myers, 1998; Myers and Macnaghten, 1999; Puchta and Potter, 1999, 2002, 2004). While Myers and Macnaghten studied social science focus groups, Puchta and Potter's work focused on market research groups. Both strands of work, however, highlight the complexity of group interaction and the way individual opinions are an interactional product, and what the role of terms such as opinion and belief is in focus group settings. For example, Puchta and Potter (2004) document how terms such as opinions or beliefs have practical tasks in eliciting certain kinds of answers (e.g. quick answers) and head off certain kinds of troubles (e.g. asking the researcher questions). Asking for spontaneous contributions and requesting first reactions (Puchta and Potter, 1999) seems to have a similar function as it implies that everybody can cooperate: after all, everyone is taken to have first reactions. These studies are rooted in CA and DP. They draw on the DP critique of standard treatment of attitudes as decontextualized mental phenomena (Billig, 1989, 1992, 1996; Myers, 1998; Potter, 1998; Potter and Wetherell, 1987, 1988; Verkuyten, 1998; Wiggins and Potter, 2004) as well as a CA approach to evaluative assessments (Pomerantz, 1984). 


\section{Materials}

A sample of 13 market research focus groups (9 German and 4 English) run by 11 different moderators was used in this study. Two focus groups were run by two moderators. Most of the time, however, these two moderators divided their task in such a way that - regarding a certain topic - one moderator was more active, while the other one was more passive. In addition, 8 German social science focus groups run by three different moderators were included in the project. The cross country comparison is at least suggestive of the generality of the phenomenon across different languages and cultural settings.

The moderators worked with planned question guides, but were free to change questions during the course of a group. However, as they have to write a report on the results of the focus groups based on the planned questions, they rarely deviate too far from the guide. The market research focus groups are routinely watched from behind the one-way mirror by the client (for example by product managers) and the advertising agency, which developed the material being discussed in the focus group (for example packet design or adverts).

Market research focus groups are routinely video-recorded; social science focus groups are routinely audio-recorded. All participants to the study consented to the focus groups being recorded for research.

\section{Analytic procedures}

Each focus group lasted for 90 minutes or more; the number of participants varied from 7 to 11 . Two market research focus groups were transcribed from beginning to end, segments of 30 minutes from the other 11 market research focus groups and the opening sequence from every market research focus group were also transcribed. The social science focus groups are not transcribed. They were watched and checked for the phenomena of interest.

The market research focus groups were transcribed in standard Jeffersonian form; see Hutchby and Wooffitt (1998) for details on transcription techniques and an overview of the used transcription symbols at the end of the article. The analysis worked with the combination of digitized recording and transcript.

The German focus groups transcripts were translated into English; all translations were checked by a bilingual English speaker. We discussed, from case to case, how best to transfer pauses and characteristics of speech production such as emphasized sounds from the German original to the English translation.

To give an indication of the distribution and prevalence of repeat receipts we did a general search of the data set. A rough count shows that repeat receipts are recurrent in market research groups. We estimate that there are typically between 15 to 20 repeat receipts in a 90 minutes long market research focus group. However, we did not find one example of a repeat receipt 
in our sample of 8 social science focus groups run by three different moderators on three different topics (media consumption; discussion with employees during a merging process; discussion with employees of a big company regarding work satisfaction).

The specific analytic procedures we have drawn on are familiar from conversation analysis (Heritage, 2004; Hutchby and Wooffitt, 1998; ten Have, 1999) and discursive psychology (Potter, 2003, 2004).

\section{Analysis: repeat receipts as a data visibility producer}

Let us come back to moderator Rick. He is asking participants to imagine the brand under consideration as a person and to describe the characteristics of that person. This kind of question is popular in market research and is called a projective question. Projective questions are considered to provide particularly deep output and are underpinned by psychoanalytic theory that suggests that market researchers need to penetrate the surface consciousness of rational thinking and socialization to deeper desires and fears (Branthwaite and Lunn, 1985). Any gross inspection of the market research focus group tapes shows the prevalence of such projective questions that could be played in a similar way at parties. Whereas at parties the question might be 'If friend $\mathrm{x}$ was a flower, which flower would (s)he be?', in the focus groups we find questions such as 'If the brand $\mathrm{x}$ was a person, what kind of person would it be?'.

The participants' answers are receipted by moderator Rick by repeating them. Let us lay out some basic features of these repeatings.

EXTRACT 1

\begin{tabular}{|c|c|c|c|}
\hline $\begin{array}{l}1 \\
2\end{array}$ & M: Rick & $\begin{array}{l}\text { And the characteristics of this } \uparrow \text { pe:rson } \\
(. \text { ) if you can imagine them, }\end{array}$ & $\begin{array}{l}\text { projective } \\
\text { question }\end{array}$ \\
\hline 3 & & & \\
\hline 4 & Mary & $\underline{\text { Powerful, }}$ & \\
\hline 5 & & $()$. & moderator \\
\hline 6 & & & looks \\
\hline 7 & & & round room \\
\hline $\begin{array}{r}\rightarrow 8 \\
9\end{array}$ & M: Rick & ${ }^{\circ}$ Powerful, ${ }^{\circ}$ & $\begin{array}{l}\text { repeat } \\
\text { receipt }\end{array}$ \\
\hline $\begin{array}{l}10 \\
11\end{array}$ & Hannah & $\begin{array}{l}\mathrm{DOMIN} \downarrow \mathrm{ANT} \\
\text { (. ) }\end{array}$ & \\
\hline$\rightarrow 12$ & M: Rick & Dominant, & repeat \\
\hline 13 & & & receipt \\
\hline 14 & & & moderator \\
\hline 15 & & & looks \\
\hline 16 & & & round room \\
\hline 17 & & (1.4) & \\
\hline 18 & Hannah & perhaps $=$ a bit daring also, & smiles \\
\hline 19 & M: Rick & $\mathrm{Da}-$ & starts to \\
\hline 20 & & & repeat \\
\hline
\end{tabular}


In Extract 1, Mary offers 'powerful' as a characteristic of the brand as person. Immediately the moderator scans the room, which he continues to do as he repeats the description with a non-final or 'list-like' intonation ( ' line 8). This both presents the brief descriptive answer as sufficient (he is not after any elaboration) and works to elicit further contributions by other participants. Hannah then provides another one word description 'dominant' - that gets a repeat receipt from moderator Rick ('Dominant,'; line 12). Note again the rising intonation of the moderator's repeat. Contrast this with a classroom situation where a teacher repeats pupils' suggestions by a completing intonation. In the focus group there is no right answer, although there may be the right kind of answer.

Note that repeats can orient to next speakers in this way or they can be oriented exclusively to the prior (to indicate trouble, say, and generate clarification or elaboration). In this article will be considered the former class of repeats; see Puchta and Potter, 1999, for detailed discussion of the latter class.

In analysing how repeat receipts are used by the moderator to provide templates for future answers we will highlight the way the moderator (a) repeats descriptions in a simple discursive format - that is, as decontextualized statements; (b) repeats contributions without differentiating between the different authors as if of one voice; and (c) repeats potentially contradictory contributions as discrete statements.

\section{Repeating decontextualized statements}

Everyday talk contains a rich set of resources for doing evaluation. This is not surprising as this is something central to interaction. Evaluations can be offered as uniquely subjective: 'personally I hated this advert' or as objective qualities in the world that others might be expected to share: 'the advert was dreadful'. In addition to these different ways of marking evaluation, people can offer descriptions of things that categorize them, or highlight some of their features: 'this packet is discreet'. In market research focus groups and sometimes in social science ones too, evaluations of the brand under discussion (or the organization or the service) are also requested with the help of substantives when the moderator asks for anthropomorphizations as in projective questions.

The following extract revolves around such a projective question. We enter the scene at the point where the participants have finished their previous task. They were asked to consider the soap packets on the table as people who went to a party and to decide which groups might be formed over the course of the evening; which means who - which brand as person - talks with whom. The moderator asks thereafter what the group with the person London (this is a pseudonym for a soap brand) is talking about and addresses repeats of the prior speaker's answer four times as prompts to potential next speakers; see the arrowed turns. The following interaction is rather complex. We would like 
to focus our analysis on how the moderator repeats the participants' contributions and we will see how he repeats them as decontextualized statements in a simple discursive format.

EXTRACT 2

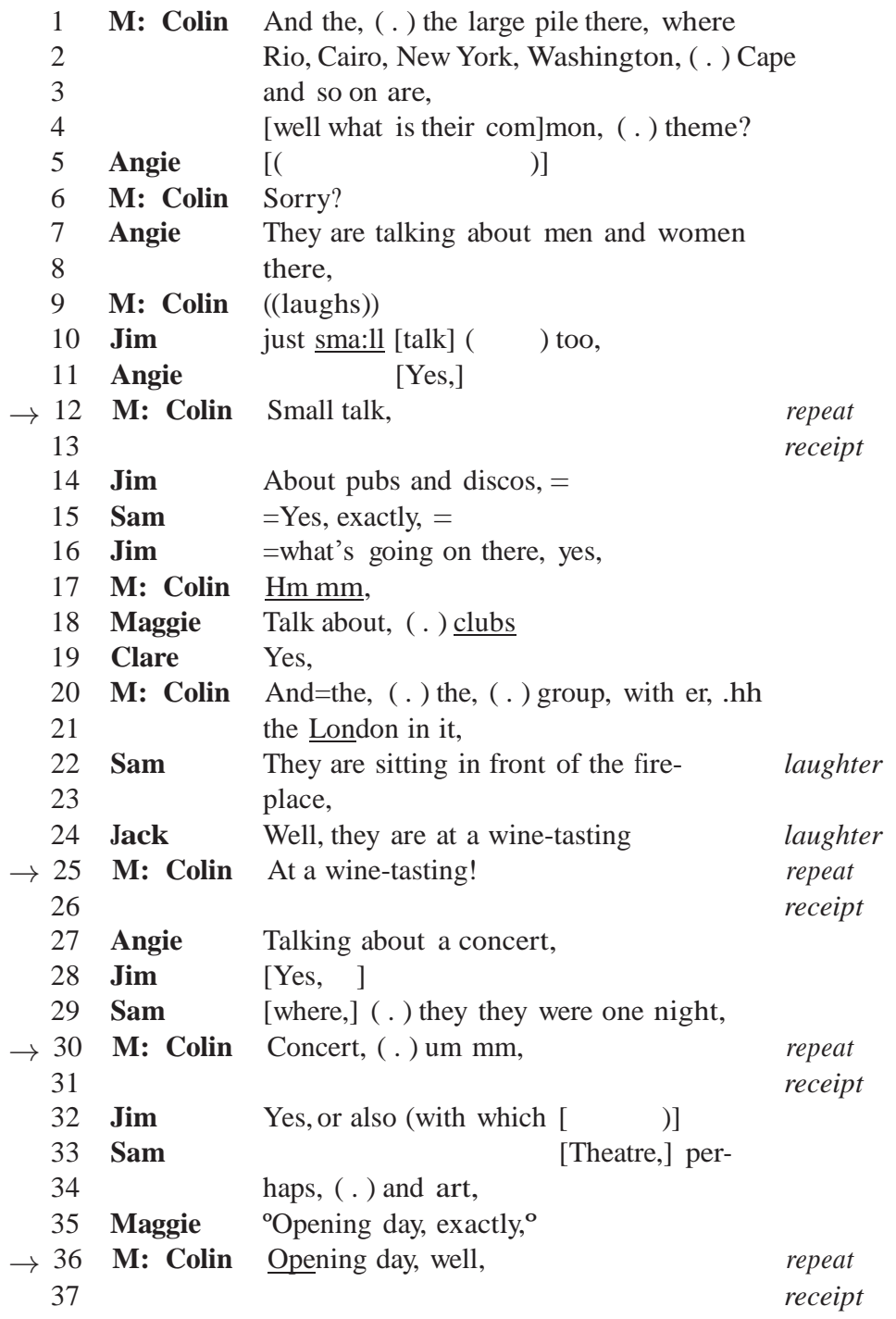

At first moderator Colin partially repeats Jim's 'just sma:ll [talk] ( ) too,' (line 10) as 'Small talk,' (line 12) and addresses this repeat to other members of the group; it is, however, the same speaker (Jim) who continues speaking. Similarly the moderator partially repeats Jack's 'Well, they are at a winetasting' (line 24) as 'At a wine-tasting!' (line 25). This prompt achieves questioning work as another participant (Angie) without having been asked 
explicitly offers 'Talking about a concert,' (line 27). After the moderator's next repeat 'Concert, (.) um mm,' (line 30), Jim offers a longer - partly unintelligible - statement about what the group at the party might talk about and we would like to focus here on another participant's (Maggie) suggestion 'Opening day, exactly, ${ }^{\circ}$ (line 35). Whereas the first three contributions were offered in more complex discursive frames, the last one adopts the form of the moderator's repeats.

In the extract above the participants treat the projective question about the conversational topic of brands that meet at a party as a story that they are going to tell in a joint manner. See, for example, the interaction between Angie, Jim and Sam in lines 27 until 29. Angie's 'talking about a concert,' (line 27) is confirmed by Jim (line 28) and further elaborated by Sam ('[where,] (.) they they were one night,' (line 29). Moderator Colin, however, only repeats 'concert'. He receipts the contribution in a way that strips off contextual and elaborative material and signals the discursive format of the required answers. The participants show they understand what is required by, finally, falling into the pattern of offering simple and formulaic responses ( ${ }^{\circ}$ Opening day, exactly, ${ }^{\circ}$; line 35 ). With the help of repeat receipts, the moderator provides a template of the required output. The required output is not a jointly narrated story. The required output is a set of isolated statements which do not refer to the contributions of other focus group members. Repeated are decontextualized statements.

\section{Repeating contributions of different authors as if of one voice}

The last section's emphasis was on how a moderator repeats contributions by stripping them of the reference to other speakers' contributions. This section deals with another feature of the repeating device. When two or three participants provide contributions, the moderator may repeat them in a way that simply adds them together, stripping off other elements from individual contributors. This feature complements the one we described in the last section. Although the moderator accumulates the contributions of different speakers, he does not point to their different origin, but repeats them as if they were provided by one participant.

We enter the scene of the sequence of the above extract at the point where the moderator asks the participants for spontaneous reactions regarding a certain brand which we pseudonomize here as Stansted.

EXTRACT 3 (German original)

1 M: Paul =We can go into it, more

2 deeply soon, (.) be-

3 cause, $($. ) well=uh I'd

4 be interested, (.) < for

5 quite a particular rea-

6 son> also, ( . ) this
=Können wir gleich noch man vertiefend, drauf eingehen, (. ) weil, (. ) mich würde noch mal=eh interessieren, $()<.a u s$ ganz besonderem anlass $<$ auch, (. ) diese Stansted, (.8) Wenn 


\begin{tabular}{|c|c|c|c|}
\hline 7 & & $\underline{\text { Stansted, }}$ ( .8 ) If you & sie jetzt mal *alle, (. ) sich \\
\hline 8 & & would just now *all, ( . ) & jetzt mal versuchen, sonen \\
\hline 9 & & just now try, to kind of & bisschen eh, ${ }^{*}(($ spricht sehr \\
\hline 10 & & concentrate a little bit & zögerlich))( . ) auf die Stan- \\
\hline 11 & & uh, ${ }^{*}(($ speaks very hesi- & sted zu konzentrieren $=$ was \\
\hline 12 & & tantly)) $($.$) on the$ & fällt Ihnen da spontan \\
\hline 13 & & Stansted=what comes to & ein=>sie können jetzt alle, $<$ \\
\hline 14 & & mind immediately $=>$ you & (. ) durcheinander reden, (. ) \\
\hline 15 & & can all, $<$ talk now at & ich brauch Sie also nicht \\
\hline 16 & & the same time, $()$. & aufzurufen. \\
\hline 17 & & well I don't need to & \\
\hline 18 & & pick on you. & \\
\hline $\begin{array}{l}19 \\
20\end{array}$ & Sven & $\begin{array}{l}\text { I can't say that! } \\
\text { ((laughs)) }\end{array}$ & $\begin{array}{l}\text { Das kann ich nicht sagen! } \\
((\text { lacht }))\end{array}$ \\
\hline 21 & Laura & ((laughs)) (Really!) & $(($ lacht $))($ Echt! $)$ \\
\hline 22 & Klara & $(($ laughs loudly $))$ & $(($ lacht laut $))$ \\
\hline $\begin{array}{l}23 \\
24\end{array}$ & some & $\begin{array}{l}\text { ((talk, laugh and cough } \\
\text { in the background }) \text { ) }\end{array}$ & $\begin{array}{l}((\text { reden, lachen und husten im } \\
\text { hintergrund }))\end{array}$ \\
\hline 25 & M: Paul & Stansted! ( . ) Well now & Stansted! ( . ) Also eben hatten \\
\hline 26 & & we've just had it said & wir schon so was wie \\
\hline 27 & & something like & ^vo:rreiter gibts seit zehn \\
\hline 28 & & $\uparrow$ fo:rerunners around for & †ja:hren (.8) \\
\hline 29 & & 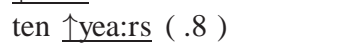 & [macht ( ) werbung,] \\
\hline 30 & & [is ( ) & \\
\hline 31 & & being advertised, ] & \\
\hline 32 & Grit & [ (White packet,) ] & [ (Weisse packung,) \\
\hline 33 & Mod. & What & Was? \\
\hline 34 & Grit & White packet, $=$ & Weisse packung, = \\
\hline 35 & Max & $=$ Discreet & $=$ Dezent \\
\hline 36 & & $()$. & \\
\hline $\begin{array}{l}37 \\
38\end{array}$ & M: Paul & $\begin{array}{l}\uparrow \text { White }(.) \text { dis } \uparrow \text { creet }(.) \\
\text { what else?= }\end{array}$ & $\begin{array}{l}\uparrow \text { Weiss (. ) de } \uparrow \text { zent (. ) was } \\
\text { noch?= }\end{array}$ \\
\hline
\end{tabular}

When the participants display helplessness and perhaps even embarrassment in providing spontaneous reactions regarding the brand under discussion (lines 19-24), moderator Paul provides examples of the required contributions (lines 25-31). In their answers, the participants Grit and Max follow the given template:

$\begin{array}{ll}\text { Grit: } & \text { 'White packet,=' (line 34) } \\ \text { Max: } & \text { '=Discreet,' (line 35) }\end{array}$

which are shortened by the moderator into

'个White (.) dis $\uparrow$ creet' (line 37)

without distinguishing the two different authors.

This extract also shows another function of the moderator's repeating device - it allows the moderator to receipt contributions by more than one 
participant as if they were a contribution by one participant. With the help of the repeat receipts the moderator is thus able to strip off rhetorical elements that linked the original contribution with other contributions and/or to strip off the different authorship of specific contributions.

\section{Repeating potentially contradictory contributions as discrete statements}

As we saw in the last section's extract, the moderator does not differentiate between different authors of a contribution while providing a repeat receipt. That is, he accumulates the given answers. We will see in this section with the help of another extract how also potentially contradictory contributions are accumulated into an imaginary list of discrete statements.

The focus group members are in a large hall where they have been considering actual vans as well as pictures of vans. This sequence takes place after an exercise where the members of this so-called car-clinic have selected their favourite vans from a set of cut out pictures and started to provide their likes and dislikes about them.

EXTRACT 4

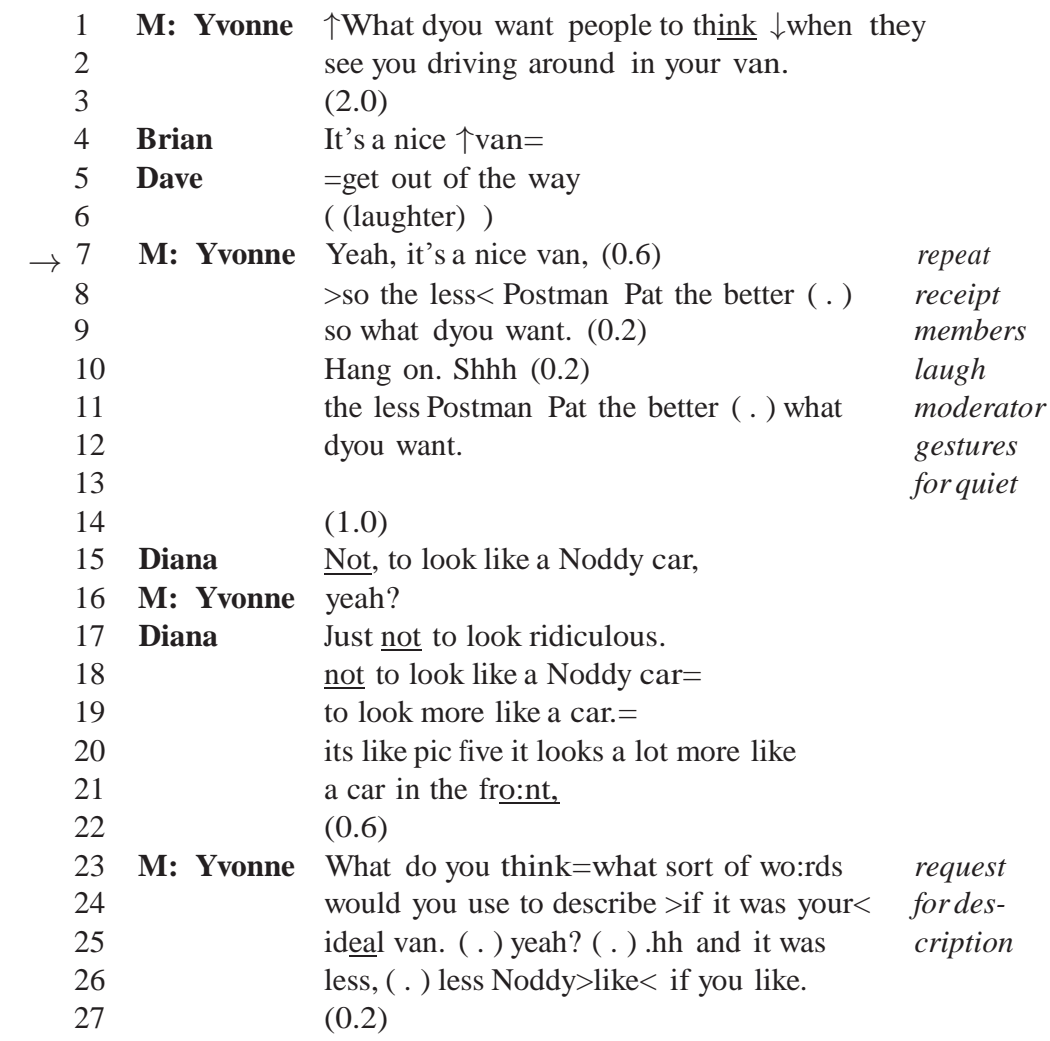




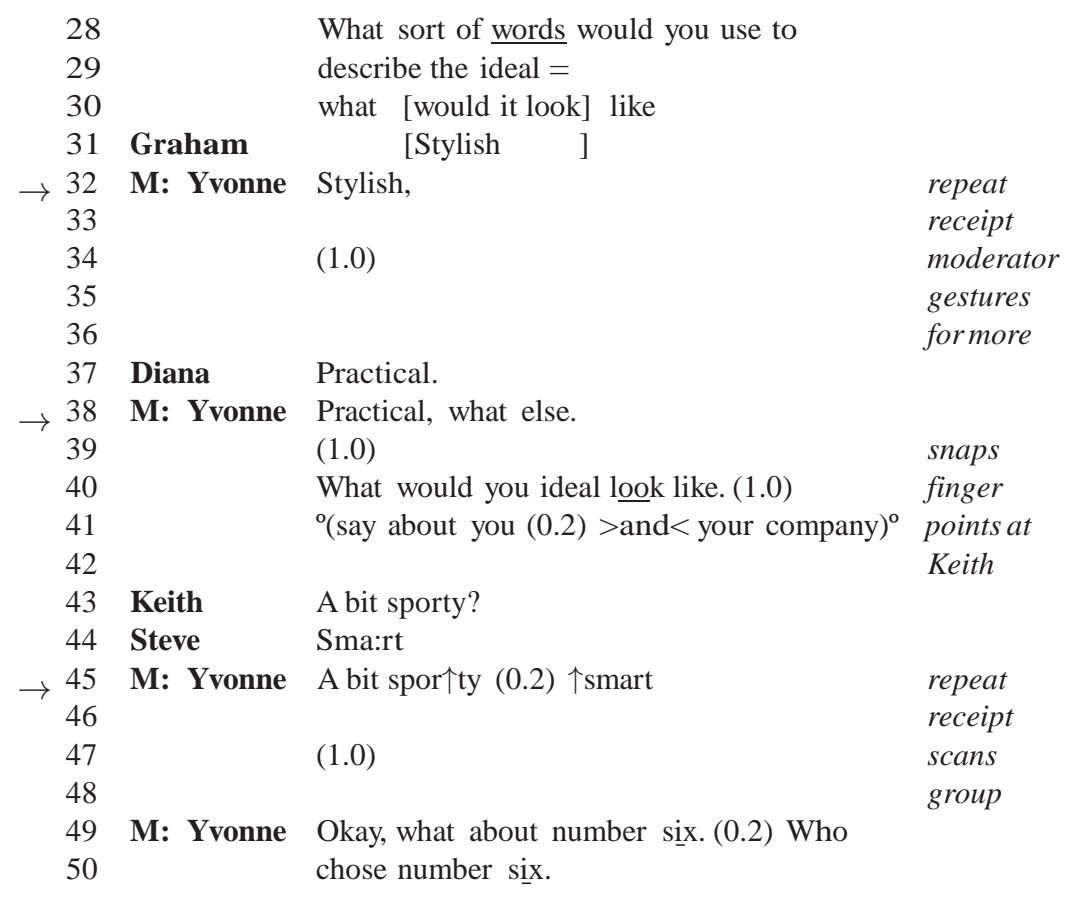

The group interaction has become hard to control - note the joking and laughing, moderator Yvonne's 'hang on' and her gestures for quiet. It has also become rather repetitive in Diana's case (note lines 15 and 18). The moderator then asks for descriptions - that is, she asks for words to describe the ideal van. This results in a classic repeat receipt sequence where the focus group participants provide one or two word descriptions and the moderator repeats them.

In looking at this complex sequence, our emphasis is on how these different individual contributions might have been discussed, debated, disputed or argued. Whereas Graham's ideal van is 'stylish', Diana's one is 'practical'. Is a stylish van also practical? Can a practical van look stylish? The moderator, however, does not point to these potential contradictions. She is not pursuing accounts that support the speaker's point of view nor is she after arguments which aim to undermine those of others. Instead, she lists the contributions as separate and discrete features of an ideal van.

So far we have demonstrated how moderators typically repeat participants' contributions by either repeating them word for word or in shortening them. Specifically moderators repeat participants' contributions (a) as isolated statements, for example by ignoring the rhetorical elements of a jointly narrated story; (b) as if made by one voice - that is, by ignoring the different authorship of contributions; and (c) as if accumulating the contributions into an imaginary list of discrete statements by ignoring potential contradictions.

In the next section, we will consider some cases where the repeat receipts are used to reword the prior speaker's utterances. 


\section{A special case: rewording and ignoring subjective evaluations}

As we mentioned earlier, evaluations can be offered as uniquely subjective ('personally I ...') or as objective qualities in the world ('this advert is ...'). With the help of this section's extracts we will see how contributions that do not display objective descriptions of the world but personal evaluations are reworded by the moderator or ignored. The extracts are taken from a focus group on a new commercial for an aftershave.

EXTRACT 5A

$\begin{array}{lll}1 & \text { M: Ann } & \begin{array}{l}\text { Right: now you've heard this story. } \\ (1.8)\end{array} \\ 3 & & \text { What kind of things went through } \\ 4 & & \text { your head? } \\ 5 & \text { Doro } & \text { I immediately thought of James Bond } \\ 6 & \text { M: Ann } & \text { James Bond. } \\ 7 & \text { Berta? } & =\text { hm hm hm hm. }= \\ 8 & \text { M: Ann } & =\text { That is James Bond, } \\ 9 & \text { Doro } & \text { Yes! Haha [ hahaha }[\text { haha } \\ 10 & \text { M: Ann } & \end{array}$

Moderator Ann's question about the kind of things that were elicited while watching the aftershave spot is answered by Doro: ' $=$ I immediately thought of James Bond' (line 5). First of all the moderator's receipt is: 'James Bond.' (line 6 ) - that is, she repeats the key word of Doro's contribution. After another focus group member displays her agreement by nodding, moderator Ann states emphatically 'That is James Bond,' (line 8). Moderator rewords Doro's answer. It is no longer about Doro's thoughts and her associations, but it is about James Bond himself!

When we follow the discussion in this focus group, shortly after the sequence presented above we find the following snippet of interaction where members display their personal likings. The thing to note here is that the moderator does not repeat precisely.

\begin{tabular}{|c|c|c|}
\hline 1 & M: Ann & $=$ Yes,$=\uparrow I s$ that \\
\hline 2 & & [个so ] \\
\hline 3 & Alexa & ['now ] I think it's great ${ }^{\circ}=$ \\
\hline 4 & Member ? & $=\mathrm{ha}$ \\
\hline 5 & Alexa & It's like you know it's just how you \\
\hline 6 & & expect it you know. \\
\hline 7 & Lena & I like it. \\
\hline $\begin{array}{l}8 \\
9\end{array}$ & Alexa & $\begin{array}{l}\text { I like it too, but }(. \text {. ) it's just nothing } \\
\text { different, [let's put it that way] }\end{array}$ \\
\hline$\rightarrow \begin{array}{l}10 \\
11\end{array}$ & $\begin{array}{l}\text { M: Ann } \\
\text { Alexa }\end{array}$ & $\begin{array}{l}\text { [Yes it's nothing ] different, } \\
\text { not taken from life= }\end{array}$ \\
\hline 12 & M: Ann & $=$ It's not taken, from life, life was some- \\
\hline
\end{tabular}


13

14 thing different, > why should people say

they like it?< (what's that,)

Lena's evaluation ('I like it'; line 7) is followed by Alexa's ('I like it too, but (.) it's just nothing different,'; lines 8 \& 9). Moderator Ann does not repeat for example 'You like it too', but she repeats 'It's nothing different,' (line 10). This repeat stands as a record of what is important, and what is important are not Lena's or Alexa's likings, but the objective quality of the commercial . . it is not different.

These extracts are from a rather unusual case where participants have built their contributions to be their subjective view and their subjective evaluation, and not as descriptions like the ones we looked at in the preceding sections. In this case we see the moderator repeats them in a way that builds them as general features of the object under discussion - that is, the repeats are used to normalize them to what is more standard for groups of this kind.

It might be thought, of course, that market research focus groups are all about evaluations and especially about personal likings and dislikes. However, what we see, pervasively, is an emphasis on descriptions. In the next section we will try and show why there should be this focus.

\section{Repeat receipt sequences after troubling evaluative sequences}

According to the market researcher Greenbaum (1998), market research focus groups are designed to capture the consumers' evaluations of, for example, new products, advertising copy and packaging, as well as identifying the reasons that consumers have for those evaluations. The central point of focus groups is to make consumers' evaluations visible. Evaluation talk, however, follows a very basic pattern. Pomerantz (1984) has shown that when one speaker offers an evaluation, i.e. an assessment of something - a meal, a film, the weather, whatever - the person he or she is talking to will, typically and very regularly, offer an evaluation of her or his own, i.e. a second assessment. Indeed, if the next speaker does not offer one, this will often be taken as a disagreement with what came before. Such evaluation-evaluation sequences are often followed by long-winded accounts and they can lead to complicated arguments about which accounts in specific and which views in general are the better ones.

Let us illustrate this with an example. In the following extract we can see how a moderator terminates a confusing and potentially troubling evaluation-evaluation sequence by asking for descriptions and by repeating a provided description. This switch happens just when the group is getting rather complex and where members are starting to offer accounts and qualifications on what they are saying. The extract comes from a group concerned with cars and their interior detailing. Before we enter the scene the participants have agreed that one of the colourful fabric swatches on display is not suitable for them as it seems to be designed for young people rather than families. Then one participant (Saul) changes his expressed position and suggests that it could look 'quite nice'. 
EXTRACT 6

\begin{tabular}{|c|c|c|c|}
\hline 1 & Saul & $=$ I think it’s nice to get awa:y (>if you & evaluation \\
\hline 2 & & see $<$ ) from the slate grey and flannels (. ) & \\
\hline 3 & & they look like (they got here) $(.)^{\circ} \mathrm{can}$ & \\
\hline 4 & & we, ${ }^{o}=$ & \\
\hline 5 & Member? & $={ }^{\circ} \mathrm{hm}^{\mathrm{o}}=$ & \\
\hline 6 & Saul & $=$ And, $($.$) it's very hard to, ($.$) just: see$ & \\
\hline 7 & & it's like choosing a piece of wallpaper $=$ & \\
\hline 8 & others & ye: $[\mathrm{ah}, \quad]$ & \\
\hline 9 & Saul & [or $(\quad$ ) ] [I mean if you see] (it) & \\
\hline 10 & & spread out it's easier to) imagine in the & \\
\hline 11 & & vehicle & \\
\hline 12 & Member ? & {$[($} & \\
\hline 13 & M: Mike & $>\mathrm{hm} \mathrm{hm} . \mathrm{hm} \mathrm{mm.<}$ & starts to \\
\hline 14 & & & intervene \\
\hline 15 & Saul & In some ways it's $(\quad)$ better than: $()$. & evaluation \\
\hline 16 & & than- than I think it could, $($.$) it$ & \\
\hline 17 & & could=>it could & \\
\hline 18 & & [look quite nice< $\quad$ ] & \\
\hline 19 & Member? & {$[>\text { might }<\text { be o } \uparrow \text { kay }=]^{o}$ yeah, ${ }^{o}$} & \\
\hline 20 & & $(($ lines omitted $))$ & \\
\hline 21 & M: Mike & The longer you're looking at it you're & further \\
\hline 22 & & warming up to $=$ & interven- \\
\hline 23 & & & tion \\
\hline 24 & Saul & =yeah! (. ) a little bit & qualifica- \\
\hline 25 & & & tion of \\
\hline 26 & & & earlier \\
\hline 27 & & & evaluation \\
\hline 28 & Gisa & $>$ (If it’s just), discreetly u:sed & ditto \\
\hline 29 & M: Mike & {$\left[\left(y^{\prime}\right.\right.$ know not the whole $($.$) thing =$ and, $\left.)\right]$} & \\
\hline 30 & Saul & [(depends how you choose yeah) ] & ditto \\
\hline 31 & Carl & I think it's a matter of $>$ sitting in the & ditto \\
\hline 32 & & car anyway. $<=$ one=once they're in the car & \\
\hline 33 & & you probably say 'Oh yeah & \\
\hline 34 & & [that's quite nice'] & \\
\hline 35 & M: Mike & {$\left[\left(\begin{array}{lll}( & )\end{array}\right](\right.$.$) (this is it) ()$.} & asking for \\
\hline 36 & & this is & descrip- \\
\hline 37 & & & tions \\
\hline 38 & & $()$. & \\
\hline 39 & Brian & Loud & \\
\hline 40 & M: Mike & Lou:d & repeat \\
\hline 41 & & & receipt of \\
\hline 42 & & & a provided \\
\hline 43 & & & descrip- \\
\hline 44 & & & tion \\
\hline 45 & & $(0.6)$ & \\
\hline 46 & Carl & $>($ true $)<=$ & \\
\hline 47 & M: Mike & $=<$ Younger $>$ person's er $(0.2)$ y'know & \\
\hline 48 & & <immature,> (. ) & \\
\hline
\end{tabular}


For a market researcher the first section of this extract is problematic as Saul and members of the group start to suggest that the whole task - that is, the commenting on fabrics out of context - is inappropriate. Moderator Mike intervenes with some quick ' $\mathrm{hms}$ ' which show some impatience and implies that they should move on. Another moderator problem arises when Saul and others qualify their prior assessments of the fabric. Mike changes then the questioning mode to one that requires descriptions of the fabric. This takes the form of a quick sentence completion task: this is . . where a member has to fill in a quality or characteristic. In this case it is Brian who completes the sentence with 'Loud' (line 39); Mike repeats 'Lou:d' (line 40) to signal the worthiness of the answer.

The key point to note here is that eliciting descriptions instead of evaluations means that a variety of different contributions can be generated without the members needing to justify them and to provide long-winded accounts for them. They can sit unchallenged next to each other and are perhaps being treatable as complementary aspects of one phenomenon such as different facets of a packet (see extract 3).

Where in groups do sequences with repeat receipts appear? Three environments are common. Firstly, they appear after troubling evaluative sequences as in the extract above. Secondly, they appear after troubling sequences in general when the focus group members seem to need some tuition about what kind of answers are required (see extracts 3 and 4). Thirdly, moderators occasionally start sequences of repeat receipts as part of a progression through prescribed topics out of the topic guide (see extracts 1 and 2). While in this section we considered the occasions on which sequences of repeat receipts appear, the next section considers how the participants are socialized into producing descriptions.

\section{Socializing the participants}

So far we have suggested that the moderators' task is, in effect, to elicit evaluative talk yet avoid common features of evaluative talk. In orienting to the practice of repeating descriptions, moderators elicit contributions without long-winded accounts for the given evaluations and without possible arguments about which accounts and which views are the better ones. Because evaluation talk is complex talk in which assessments follow assessments and accounts other accounts, moderators switch in troubling evaluation-evaluation sequence to a different mode of questioning - that is, to a descriptive mode.

With the help of repeat receipt sequences, the moderator both controls the interaction and elicits compact, concise and easy to understand talk. The following pattern of interaction is very common in focus groups. Schematically it will look like this: 


\begin{tabular}{lll} 
TAB LE 1 & directly or indirectly \\
\hline Moderator & $\begin{array}{l}\text { asks for } \\
\text { description } \\
\text { provides } \\
\text { description } \\
\text { repeats } \\
\text { description } \\
\text { Moderator }\end{array}$ & may then orient to further members \\
Member 2 & $\begin{array}{l}\text { description } \\
\text { repeats } \\
\text { description }\end{array}$ & and so on $\ldots$ \\
Moderator &
\end{tabular}

There are two points to highlight about this pattern of interaction: (a) It concentrates on descriptions rather than evaluations. These descriptions may be qualities or aspects of products. Usually these descriptions display evaluations. They are typically produced without accounts or qualifications. (b) It is talk that goes via the moderator who provides a repeat of each description.

Many of the features of this practice are found in a refined way in their use of the whiteboard technique that is a common practice in market research focus groups. Near the start of focus groups moderators often collect contributions of some kind and write them onto a flip-chart or whiteboard. According to moderators this exercise has the virtue of getting all participants involved in the interaction at an early stage. Our analysis of the repeat receipts, however, helps us better understand the interactional work done by the whiteboard. We can see that repeat receipts act as a kind of interactional whiteboard.

The following is taken from a focus group concerned with shampoo adverts. At the start of the group the participants have been shown a video of a shampoo advert.

EXTRACT 7

M: Martha Just tell me em, what sorts of things came to mind not necessarily what you wrote down. but what sorts of things came to mind when I showed you that film just literally the first sort of thoughts

In what follows, the participants offer a variety of ideas and thoughts - some are more, some are less complex. Moderator Martha, however, writes down just a word or two on her flip-chart. What she does is the equivalent of a repeat receipt. Having asked for descriptions (note - she has not asked participants' opinions of the advert, or whether they liked it) she strips off all except key words. At this early stage in the group the whiteboard exercise provides a lesson in focused talk. The interactional pattern is the same as for repeat receipts: 


\begin{tabular}{lll} 
TABLE2 & & \\
\hline Moderator & $\begin{array}{l}\text { asks for } \\
\text { description } \\
\text { provides } \\
\text { description } \\
\text { writes down key } \\
\text { word or words } \\
\text { provides further } \\
\text { Mescription } \\
\text { Member } 2\end{array}$ & afew words or a phrase \\
Moder 2 & then orients to next member \\
description & and so on ...
\end{tabular}

While we looked in this section at how participants are socialized into producing certain kinds of contributions (that is descriptions), the next section is on the kind of contributions which are considered as noteworthy. We will see how what is considered as noteworthy is similar to the moderators' repeat receipts we analysed in the last sections.

\section{Making data visible}

As mentioned at the beginning, companies and organizations that commission focus groups pay for three kinds of output: to watch the interaction from behind a one-way mirror and to receive both a video of the interaction and a report of the interaction written by the moderator. This report typically summarizes themes and gives sample quotes of participants' views. Usually a focus group moderator is on her or his own. In our sample, however, there are two focus groups that are run by two moderators, a senior and a junior one who is going to learn this job. One of these two focus groups provides us with the following sequence in which the junior moderator writes the protocol and gets a clear instruction on what to write - that is, the next extract allows us to witness the development of a protocol in action! We are interested in when the senior instructs the junior and, especially of course, in the instruction itself. What does the moderator consider as noteworthy for the report? We will see how the senior moderator prompts the junior one with what looks like the repeat receipts we met up to now - that is, the moderator strips off the rhetorical elements which linked the participants' contributions to the ones of others. By realizing that what is considered as noteworthy bears the feature of a repeat receipt, we learn what the practice of repeat receipts is doing and why it should be there: to produce data for the report (and the audience).

This is a focus group on chewing gum - the members were asked to taste chewing gums of the brand under discussion and to offer spontaneous comments on their taste; Berlin is a pseudonym for the chewing gum brand. 


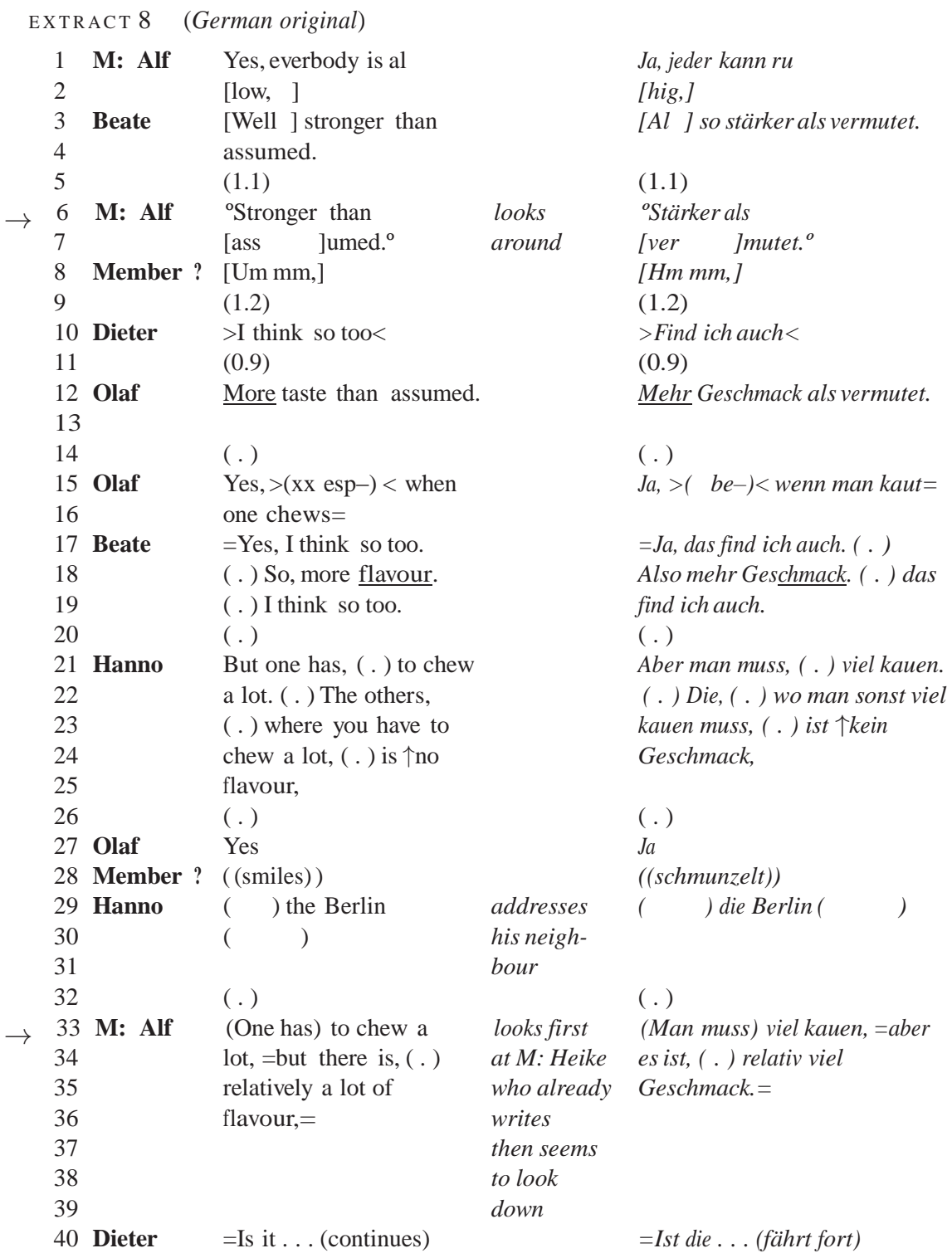

When members start talking with each other, the senior moderator (Alf) signals to the junior one (Heike) that certain responses should be included in the protocol and he says to her indicating that the following is to be written down:

'(One has) to chew a lot,=but there is, (.) relatively a lot of flavour,=' (lines 33-6)

When we analyse the members' contributions before, we see that this is not a proper repeat, as nobody said this. Here is a list of those contributions that resemble the moderator's statement: 
Hanno offered that 'But one has, (.) to chew a lot.' (lines 21 and 22)

Olaf said before: 'More taste than assumed.' (line 12)

Beate agrees with Olaf in saying: 'Yes, I think so too. (.) So, more flavour. (.)

I think so too.' (lines 17-19)

In his summarizing repeat, moderator Alf does not distinguish the different authors and he treats their contributions as if produced by one voice. In combining several responses, two modifications compared with the original responses are noteworthy. Firstly, the moderator states that although one has to chew a lot, there is relatively a lot of flavour. Hanno, however, formulated his statement in contrast to the prior speakers: there is flavour, but one has to chew a lot. Secondly, almost all members used relative descriptions: 'stronger than assumed', 'more taste than assumed', 'more flavour'. The moderator, however, puts his statement in absolute terms: '(One has) to chew a lot but there is relatively a lot of flavour'. Note how he adds 'relatively'!

Let us point to how the moderator here transforms contributions that are given in reaction to prior contributions into discrete data (cf. Puchta and Potter, 2002). Furthermore, let us point to the moderator's orientation to absolute formulations such as 'there is flavour', which are understandable without knowing the context ('stronger than - which brand?'; 'more flavour than what?').

The senior moderator's repeat receipt addressed to his junior colleague shows us the orientation to a certain kind of output - that is, to those contributions that are easily exploitable for the report on the focus groups and easily accessible for both the overhearing audience behind the one-way mirror and the audience that watches the video of the focus group. This special case of a repeat receipt addressed to a moderator shows us what the practice of repeat receipts is doing and why it should be there: to produce data for the report (and the audience).

\section{Discussion}

This article made a series of descriptive observations about a recurrent feature in market research focus groups: moderators recurrently provide repeat receipts of participants' contributions. Furthermore, it offered explanations as to what this basic practice is doing and why it should be here. To sum up, the repeat receipt device has a common structure - the repeats are addressed to potential next speakers with a rising intonation. It has a number of functions: (a) it can strip off rhetorical relations as decontextualized statements are repeated; (b) it can summarize contributions in repeating contributions of different authors as if of one voice; (c) it can cover conflict in repeating potentially contradictory contributions as discrete statements; and (d) it can socialize responding by providing templates for the required contributions. With the help of the repeat receipts the focus group interaction is shaped in such a way as to generate visible data for the overhearing audience, the video and the report. 
The basic dilemma in market research focus groups is that while evaluations are the required output of focus groups, evaluation talk is complex talk in which assessments follow assessments and accounts other accounts. We have seen how moderators switch from troubling evaluationevaluation sequences to a different mode of questioning - that is, to a descriptive mode. When descriptions are provided they are repeated by the moderator. Let us end by comparing the repeat receipts of moderators in market research focus groups with receipts in other settings.

The first and most important comparison is with repeats in other social research settings. There is only a small amount of systematic research on this topic. Houtkoop-Steenstra (2000) has observed that answer repeats are common in standardized surveys. She suggests that through repeating an answer the interviewer can show that they have heard an answer without indicating whether they have understood it (as opposed to everyday situations, where showing understanding may be required before talk continues [p. 25]). She notes that repeating an answer can also be a way of the interviewer showing that they are writing, thus maintaining the smooth coherence of the interaction (p. 26). There are at least three crucial differences between HoutkoopSteenstra's materials and our own.

First, in standardized surveys the response is typically coded into one of a fixed, predetermined set of options. What is repeated will correspond to one of those options. One of the points of focus group research, in contrast, is to avoid the researcher determining the responses. The moderator using a repeat receipt is typically receipting terms introduced by group members.

Second, standardized interviews have just the two speakers. There is thus only one audience for the repeat: the respondent. This restricts its role to, for example, indicating that writing is being done or showing that the answer has been heard correctly. In focus groups, the other group participants are an additional relevant audience. The relevance here is that the repeat can provide a template for the kind of response that is appropriate that other respondents can follow - that is, the repeat can have a socializing role. It can also support smooth speaker transition; a series of repeats can be used as an orderly device for selecting a next speaker (see also Puchta and Potter, 2004).

Third, the recipients of survey research (academics, policy makers, politicians) will only access any individual response as part of a summary statistic (or at the most as an illustrative example). They are overhearers of the interaction in only the most distant of senses. In market research focus groups, however, the research audience (product developers, advertisers, politicians) is likely to be both present behind a one-way mirror and watching the video of the interaction. The repeat receipt can thus be more than merely a check on correct hearing or a display of writing, it can be a way of interactionally highlighting what is appropriate and significant in respondents' talk. This is what we mean when we suggest that the repeat receipt is a device for generating visible data. 
Another relevant comparison is with receipts in news interviews. As Heritage (1985) has shown, when people are told stories or items of news in everyday settings they typically provide news receipts such as 'oh' or 'did she' or offer assessments 'that's good'. News receipts are rare in focus groups and this can be compared with news interviews as they also contain only few explicit news receipts. As we have shown elsewhere (Puchta and Potter, 2004), by avoiding news receipts the moderator (like the news interviewer) presents him- or herself as not the final recipient of the information but as someone who is generating information for some other party (a company, organization or political party). Crucially, they do not present themselves as changing their knowledge state, as starting to know more about the product, as developing an expertise that might lead them to assess members' contributions. In news interviews formulations of the interviewees' responses are pervasive. Formulations construct the gist or upshot of something, going beyond the simple repetition of terms (Heritage, 1985; Heritage and Watson, 1979). Although focus groups have an overhearing audience, constructing the gist or upshot of contributions is probably too time consuming where there is a group of five or more people. The moderators' receipts are much sparser and quicker, just repeating single words. Moreover, with repeats there is less of a risk that the researcher will be seen as an expert on the product and therefore be questioned about it (Puchta and Potter, 2004).

This article has identified the interactional role of such repeat receipts. They enable moderators to shape the interaction in such a way as to treat it as easily accessible and exploitable findings - easily accessible for the live audience and the video and easily exploitable for the report that has to be written by the moderator. Like news interviewers, moderators decline the role of report recipient while maintaining the role of report elicitor. In repeating participants' contributions in this minimal way the effect is to produce an 'interactional whiteboard'. Moreover, moderators display their neutrality in just repeating members' statements and in neither assessing them nor formulating their specific features. Repeat receipts become a neat way of displaying evaluative and epistemic indifference.

TRANSCRIPTION SYMBOLS

[]

$\uparrow \downarrow$

$\rightarrow$

Underlining

CAPITALS

${ }^{\circ}$ I know it, ${ }^{\circ}$
Square brackets mark the start and the end of overlapping speech.

Vertical arrows precede marked pitch movement.

Side arrows are not transcription features but draw analytic attention to particular lines of text.

Signals speaker's emphasis.

Mark speech that is obviously louder than surrounding speech.

Raised circles ('degree' signs) enclose obviously quieter speech. 


\begin{tabular}{|c|c|}
\hline$(.8)$ & $\begin{array}{l}\text { Numbers in round brackets measure pauses longer than } 0.2 \\
\text { seconds. }\end{array}$ \\
\hline ( . ) & A pause of 0.2 seconds or less. \\
\hline$(($ text $))$ & Additional comments from the transcriber. \\
\hline *Why?* & $\begin{array}{l}\text { ((smiley voice) }) \text { Asterisks enclose characteristics of the } \\
\text { speech which is described in the brackets. }\end{array}$ \\
\hline$\because:$ & $\begin{array}{l}\text { Colons show degrees of elongation of the prior sound; the } \\
\text { more colons, the more elongation. }\end{array}$ \\
\hline hhh & Aspiration (out-breaths); proportionally as for colons. \\
\hline .hhh & Inspiration (in-breaths). \\
\hline Ye:ah, & $\begin{array}{l}\text { Commas mark weak rising intonation, as used sometimes in } \\
\text { enunciating lists. }\end{array}$ \\
\hline Ye:ah. & $\begin{array}{l}\text { Periods (stops) mark falling, stopping intonation, irrespective } \\
\text { of grammar. }\end{array}$ \\
\hline ? & $\begin{array}{l}\text { Question marks signal question intonation, irrespective of } \\
\text { grammar. }\end{array}$ \\
\hline$><$ & $\begin{array}{l}\text { Enclosed speech is produced noticeably quicker than the sur- } \\
\text { rounding talk. }\end{array}$ \\
\hline$<>$ & $\begin{array}{l}\text { Enclosed speech is produced noticeably slower than the sur- } \\
\text { rounding talk. }\end{array}$ \\
\hline & $\begin{array}{l}\text { Equals signs mark the immediate latching of successive } \\
\text { stretches of talk, with no interval. }\end{array}$ \\
\hline & Unfilled brackets mark talk that cannot be heard. \\
\hline
\end{tabular}

ACKNOWLEDGEMENTS

Parts of Claudia Puchta's and Stephan Wolff's work were supported by a grant from the Deutsche Forschungsgemeinschaft (DFG), Bonn/Germany. We would also like to thank two anonymous referees for helpful comments on an earlier draft. Finally, we would like to thank Sally Wiggins for transcribing the English focus groups.

\section{REFERENCES}

Antaki, C. (1999) 'Interviewing Persons With a Learning Disability: How Setting Lower Standards May Inflate Well-Being Scores', Qualitative Health Research 9(4): 437-54.

Antaki, C. and Rapley, M. (1996) “"Quality of Life” Talk: The Liberal Paradox of Psychological Testing', Discourse \& Society 7(3): 293-316.

Antaki, C., Houtkoop-Steenstra, H. and Rapley, M. (2000) “"Brilliant. Next Question. ..": High-Grade Assessment Sequences in the Completion of Interactional Units', Research on Language and Social Interaction 33: 235-62.

Billig, M. (1989) 'The Argumentative Nature of Holding Strong Views: A Case Study', European Journal of Social Psychology 19: 203-23. Billig, M. (1992) Talking of the Royal Family. London: Routledge.

Billig, M. (1996) Arguing and Thinking: A Rhetorical Approach to Social Psychology (2nd edn). Cambridge: Cambridge University Press. 
Branthwaite, A. and Lunn, T. (1985) 'Projective Techniques in Social and Market Research', in R.L. Walker (ed.) Applied Qualitative Research, pp. 101-21. London: Gower.

Garfinkel, H. (1967) Studies in Ethnomethodology. Englewood Cliffs, NJ: Prentice-Hall.

Greenbaum, T.L. (1998) The Handbook for Focus Group Research. Thousand Oaks, CA: Sage.

Heritage, J. (1985) 'Analyzing News Interviews: Aspects of the Production of Talk for an Overhearing Audience', in Teun A. van Dijk (ed.) Handbook of Discourse Analysis, vol. 3, pp. 95-119. London: Academic Press.

Heritage, J. (2004) 'Conversation Analysis and Institutional Talk', in K. Fitch and R. Sanders (eds) Handbook of Language and Social Interaction, [in press]. Mahwah, NJ: Erlbaum.

Heritage, J.C. and Watson, D.R. (1979) 'Formulations as Conversational Objects', in G. Psathas (ed.) Everyday Language: Studies in Ethnomethodology, pp. 123-62. New York: Irvington.

Houtkoop-Steenstra, H. (1995) 'Meeting Both Ends: Standardization and Recipient Design in Telephone Survey Interviews', in P. ten Have and G. Psathas (eds) Situated Order: Studies in the Social Organization of Talk and Embodied Activities, pp. 91-106. Washington, DC: University Press of America.

Houtkoop-Steenstra, H. (1996) 'Probing Behavior of Interviewers in the Standardized Semi-Open Research Interview', Quality and Quantity 30: 205-30.

Houtkoop-Steenstra, H. (1997) 'Being Friendly in Survey Interviews', Journal of Pragmatics 28: 591-623.

Houtkoop-Steenstra, H. (2000) Interaction and the Standardized Survey Interview: The Living Questionnaire. Cambridge: Cambridge University Press.

Hutchby, I. and Wooffitt, R. (1998) Conversation Analysis: Principles, Practices and Applications. Cambridge: Polity Press.

Maynard, D.W. and Schaeffer, N.C. (1997) 'Keeping the Gate: Declinations of the Request to Participate in Telephone Survey Interview', Sociological Methods and Research 26: 34-79.

Maynard, D.W. and Schaeffer, N.C. (2000) 'Standardization and its Discontents', in D.W. Maynard, H. Houtkoop-Steenstra, N.C. Schaeffer and J. van der Zouwen (eds), Standardization and Tacit Knowledge: Interaction and Practice in the Survey Interview, pp. 3-46. New York: Wiley.

Maynard, D.W., Houtkoop-Steenstra, H., Schaeffer, N.C. and Van der Zouwen, J. (2002) Standardization and Tacit Knowledge: Interaction and Practice in the Survey Interview. New York: Wiley.

Myers, G. (1998) 'Displaying Opinions: Topics and Disagreement in Focus Groups', Language in Society 27(1): 85-111.

Myers, G. and Macnaghten, P. (1999) 'Can Focus Groups be Analysed as Talk?', in R.S. Barbour and J. Kitzinger (eds) Developing Focus Group Research, pp. 173-85. London: Sage.

Pomerantz, A.M. (1984) 'Agreeing And Disagreeing with Assessments: Some Features of Preferred/Dispreferred Turn Shapes', in J.M. Atkinson and J. Heritage (eds) Structures of Social Action: Studies in Conversation Analysis, pp. 57-101. Cambridge: Cambridge University Press.

Potter, J. (1998) 'Discursive Social Psychology: From Attitudes To Evaluative Practices', European Review of Social Psychology 9: 233-66.

Potter, J. (2003) 'Discourse Analysis', in M. Hardy and A. Bryman (eds) Handbook of Data Analysis, pp. 607-24. London: Sage. 
Potter, J. (2004) 'Discourse Analysis as a Way of Analysing Naturally Occurring Talk', in D. Silverman (ed.) Qualitative Analysis: Issues of Theory and Method (2nd edition), pp. 200-21. London: Sage.

Potter, J. and Wetherell, M.(1987) Discourse and Social Psychology: BeyondAttitudes and Behaviour. London: Sage.

Potter, J. and Wetherell, M. (1988) 'Accomplishing Attitudes: Fact and Evaluation in Racist Discourse', Text 8: 51-68.

Puchta, C. and Potter, J. (1999) 'Asking Elaborate Questions: Focus Groups and the Management of Spontaneity', Journal of Sociolinguistics 3: 314-35.

Puchta, C. and Potter, J. (2002) 'Manufacturing Individual Opinions: Market Research Focus Groups and the Discursive Psychology of Evaluations', British Journal of Social Psychology 41: 345-63.

Puchta, C. and Potter, J. (2004) Focus Group Practice. London: Sage.

Rapley, M. (2001) 'The Art(fulness) of Open-ended Inteviewing: Some Considerations on Analysing Inteviews', Qualitative Research 1(3): 303-24.

Rapley, M. and Antaki, C. (1996) 'A Conversation Analysis of the "Acquiescence" of People with Learning Difficulties', Journal of Community and Applied Social Psychology 6: 207-27.

Schaeffer, N.C. and Maynard, D.W. (1996) 'From Paradigm to Prototype and Back Again: Interactive Aspects of Cognitive Processing in Standardized Survey Interviews', in N. Schwarz and S. Sudman (eds) Answering Questions: Methodology for Determining Cognitive and Communicative Processes in Survey Research, pp. 65-88. San Francisco, CA: Jossey-Bass.

Suchman L. and Jordan, B. (1990) 'Interactional Troubles in Face-to-Face Survey Interviews', in Journal of the American Statistical Association 85: 232-41.

ten Have, P. (1999) Doing Conversation Analysis. London: Sage.

Verkuyten, M. (1998) 'Attitudes in Public Discourse: Speakers' Own Orientations', Journal of Language and Social Psychology 17(3): 302-22.

Wiggins, S. and Potter, J. (2003) 'Attitudes and Evaluative Practices: Category vs. Item and Subjective vs. Objective Constructions in Everyday Food Assessments', British Journal of Social Psychology 42: 513-31.

CLAUDIA PUCHTA is an active market researcher with many years of practical experience in moderating groups. She is a professor at the University of Applied Sciences in Lueneburg, Germany, where she teaches qualitative methods. She is author, with Jonathan Potter, of Focus Group Practice (Sage, 2004). Together with Stephan Wolff she works in a research project sponsored by the Deutsche Forschungsgemeinschaft, Bonn, on focus groups.

Address: Business of Applied Sciences, Department of Business Psychology, Wilschenbrucher Weg 84, 21335 Lüneburg, Germany. [email: Claudia.Puchta@ t-online.de]

JONATHAN POTTER has researched a range of topics including racism, relationship counselling and child protection helplines, and has written extensively on meta-theory, theory and methods in the area of discourse analysis and discursive psychology. His most recent books are Representing Reality (Sage, 1996), Focus Group Practice (with Claudia Puchta, Sage, 2004) and Talk and Cognition (edited with Hedwig te Molder, CUP, in press). He is Professor of Discourse Analysis at Loughborough University.

Address: Discourse and Rhetoric Group, Department of Social Sciences, Loughborough University, Leicestershire LE11 3TU, UK. [email: j.a.potter@lboro.ac.uk] 
STEPHAX vvoLFF is Professor in the Department of Social Service tvranagement and Organizational Studies and diredor of the :VIA Program 'Organization Studies' at the University of Hlldesheim. Germany. I-lls research Interests are in conversation analysis especlally ln legal settings, program evnluatlon nnrl knmNlerlge management

llddress: Univcrsiti:it Hildcshcirn. Institut fHr Sozialpi:idagogik, Samdsonptatz 1, 311-11 Hildesheim, Germany. [ernail: IVolllS:.@t-online.del 